\title{
The use of a simulator as a systematic scenario for students to learn the skill of tooth preparation
}

\author{
Sergei Vaits ${ }^{1, *}$, Tatyana Vaits $^{1}$, Fatima Daurova ${ }^{1}$, and Zarina Kodzaeva ${ }^{1}$ \\ ${ }^{1}$ RUDN University, 117198, 6 Miklukho-Maklaya str., Moscow, Russia
}

\begin{abstract}
The purpose of the study is to improve the efficiency of the dental specialists training, as well as to identify their relationship to learning with the use of acrylic teeth and virtual simulators. The study included 55 students of the $5^{\text {th }}$ year of the Dental Faculty of RUDN. The time spent for the preparation of I and II classes by Black was estimated. At the end of the cycle, it was revealed that when working on the virtual simulator the results were better. In addition, students were surveyed. Thus, the virtual simulator provides an innovative approach that allows creating with very high accuracy real tactile sensations and the sense of presence.
\end{abstract}

\section{Relevance of the study}

For many years, the main postulate of the medical education in Russia was "to learn by the patient's bedside". In recent years, various simulators which enable students to practice manual skills have been widely introduced into the educational process. Training on acrylic teeth is also widely spread out. However, acrylic dust and fast spoilage of artificial teeth forced to develop the most high-tech, eco-friendly and economical method, that is, training on the virtual simulators.

\section{Purpose of the study}

The purpose of the research is to improve the quality of training of the dental profile specialists, as well as to identify their attitude towards learning with the use of acrylic teeth and virtual simulators.

\section{Materials and methods}

The study was conducted at the workplace "VirTeaSy Dental", which is a unit consisting of a simulator with two screens, one of which is intended for direct work in a virtual environment, and the second screen is the one, where all actions are tracked. The kit also

\footnotetext{
* Corresponding author: swsstom@yandex.ru
} 
includes glasses for work and software. The position of the trainee on the simulator can be controlled by pneumatic control (Figure 1).

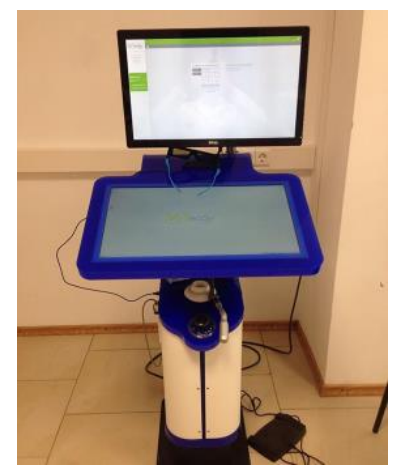

Fig. 1. "VirTeaSy Dental".

This simulator allows improving professional training of trainees, with simultaneous evaluation of their skills, and also provides an innovative approach to learning. In turn, a proven and patented technology allows simulating the clinical situation with very high accuracy and reliability [3].

The study included 55 students of the $5^{\text {th }}$ year of the RUDN Dental Faculty. All students were divided into two groups. The first one, consisting of 29 students, made preparation on the virtual simulator, and the second one that consisted of 26 students trained on acrylic teeth. The participants were offered to prepare the cavities of the classes I and II, and then an evaluation of the quality of preparation was carried out.

Before the beginning of the classes, the students should be authorized in the system. This gives an opportunity for independent practice and the implementation of various exercises and assignments, provided by the curriculum. One can save all the classes on the virtual simulator that allows reviewing them in the future. The trainee can tactilely feel the working tool, tip and mirror $[4,5]$.

After that, they were asked to anonymously answer a number of questions to identify the positive and negative aspects of these teaching methods, namely: did you like working on the simulator, do you need a complete replacement of traditional teaching methods by virtual ones, which of the methods do you consider most useful from the standpoint of acquisition of professional skills, which of the types of training would be most effective and more understandable for students' perception.

The chronometric method that is, the time spent on preparation of acrylic teeth and on a work at the virtual simulator is checked.

The sociological method that is, the anonymous questioning of students is applied.

\section{Results of the study}

Preparation of the class I cavity on acrylic teeth takes 485 seconds on average, while on the teeth of the virtual simulator it takes 502 seconds. To complete the preparation of the class II cavity on the teeth of the virtual simulator, the students took an average of 727 seconds, and on acrylic teeth - 719 seconds.

The same assessment of the preparation time was carried out at the end of the training cycle, where positive dynamics was revealed in both methods of preparation. It is established that the preparation of the class I cavity on acrylic teeth takes an average of 352 seconds, while on the teeth of the virtual simulator - 319 seconds. To complete the preparation of the class II cavity on the virtual simulator teeth, students took an average of 
539 seconds, and on acrylic teeth - 560 seconds. The time when working with acrylic teeth was fixed on the stopwatch, and when working on the virtual simulator, it was fixed directly in the simulator itself (Table 1).

Table 1. Operating time on acrylic teeth and the virtual simulator.

\begin{tabular}{|c|c|c|c|c|c|c|c|c|c|}
\hline & \multicolumn{4}{|c|}{ I class by Black } & & \multicolumn{4}{|c|}{ II class by Black } \\
\hline & Group 1 (2 & 9 students) & Group 2(2 & 6 students) & & Group 1 (2) & 29 students) & Group 2 (2 & 6 students) \\
\hline & Simı & lator & Acryli & $\mathrm{c}$ teeth & & Sim & ulator & Acryli & ic teeth \\
\hline & $\begin{array}{c}\text { Task } \\
\text { execution } \\
\text { time at the } \\
\text { beginning } \\
\text { of the cycle }\end{array}$ & $\begin{array}{c}\text { Task } \\
\text { execution } \\
\text { time at the } \\
\text { end of the } \\
\text { cycle }\end{array}$ & $\begin{array}{c}\text { Task } \\
\text { execution } \\
\text { time at the } \\
\text { beginning } \\
\text { of the cycle }\end{array}$ & $\begin{array}{c}\text { Task } \\
\text { execution } \\
\text { time at the } \\
\text { end of the } \\
\text { cycle }\end{array}$ & & $\begin{array}{c}\text { Task } \\
\text { execution } \\
\text { time at } \\
\text { the } \\
\text { peginning } \\
\text { of the } \\
\text { cycle }\end{array}$ & $\begin{array}{c}\text { Task } \\
\text { execution } \\
\text { time at the } \\
\text { end of the } \\
\text { cycle }\end{array}$ & $\begin{array}{c}\text { Task } \\
\text { execution } \\
\text { time at the } \\
\text { beginning } \\
\text { of the cycle }\end{array}$ & $\begin{array}{c}\text { Task } \\
\text { execution } \\
\text { time at the } \\
\text { end of the } \\
\text { cycle }\end{array}$ \\
\hline 1 & 8.2 & 5.37 & 8.01 & 5.59 & 1 & 12 & 8.58 & 12.01 & 9.32 \\
\hline 2 & 8.29 & 5.24 & 8.11 & 6.01 & 2 & 12.11 & 9.05 & 12.03 & 9.34 \\
\hline 3 & 8.42 & 5.42 & 8.09 & 6.02 & 3 & 12.1 & 9.08 & 12.09 & 9.38 \\
\hline 4 & 8.31 & 5.34 & 8.03 & 6 & 4 & 12.08 & 9.1 & 12.09 & 9.37 \\
\hline 5 & 8.22 & 5.31 & 8.02 & 5.59 & 5 & 12.21 & 9.11 & 11.59 & 9.24 \\
\hline 6 & 8.43 & 5.32 & 8.09 & 6.02 & 6 & 12.18 & 9.06 & 12.09 & 9.38 \\
\hline 7 & 8.22 & 5.34 & 8.07 & 5.59 & 7 & 12.1 & 8.57 & 12.02 & 9.31 \\
\hline 8 & 8.39 & 5.23 & 8.02 & 6.03 & 8 & 12.11 & 8.56 & 12.16 & 9.38 \\
\hline 9 & 8.37 & 5.31 & 8.02 & 5.59 & 9 & 12.19 & 9.08 & 11.59 & 9.36 \\
\hline 10 & 8.39 & 5.42 & 8.03 & 6.03 & 10 & 12.18 & 9.04 & 12.2 & 9.32 \\
\hline 11 & 8.35 & 5.26 & 8.09 & 6.02 & 11 & 12.21 & 8.55 & 11.58 & 9.37 \\
\hline 11 & 8.37 & 5.31 & 8.09 & 6.01 & 11 & 12.22 & 9.09 & 12.11 & 9.39 \\
\hline 13 & 8.37 & 5.43 & 8.11 & 5.59 & 13 & 12.09 & 9.11 & 12.11 & 9.33 \\
\hline 14 & 8.47 & 5.39 & 8.13 & 6.01 & 14 & 12.29 & 9.08 & 12.04 & 9.26 \\
\hline 15 & 8.45 & 5.49 & 8.06 & 6.02 & 15 & 12.35 & 9.05 & 12.09 & 9.27 \\
\hline 16 & 8.22 & 5.43 & 8.12 & 6.01 & 16 & 12.38 & 9.1 & 12.03 & 9.31 \\
\hline 17 & 8.33 & 5.41 & 8.09 & 5.59 & 17 & 12.25 & 9.11 & 12.09 & 9.32 \\
\hline 18 & 8.36 & 5.32 & 8.1 & 5.58 & 18 & 12.1 & 9.15 & 12.07 & 9.28 \\
\hline 19 & 8,47 & 5.31 & 8.12 & 6.02 & 19 & 12.08 & 9.11 & 12.03 & 9.32 \\
\hline 20 & 8,46 & 5.29 & 8.16 & 5.59 & 20 & 12.12 & 9.16 & 12.01 & 9.34 \\
\hline 21 & 8.34 & 5,25 & 8.11 & 6.01 & 21 & 12.18 & 9.15 & 12.02 & 9.37 \\
\hline 22 & 8,43 & 5.38 & 8.14 & 5.59 & 22 & 12.08 & 9.11 & 12.02 & 9.36 \\
\hline 23 & 8,32 & 5.21 & 8.11 & 6.01 & 23 & 12.11 & 9.15 & 12.05 & 9.28 \\
\hline 24 & 8.39 & 5.16 & 8.04 & 6.02 & 24 & 12.09 & 9.14 & 12.03 & 9.36 \\
\hline 25 & 8.42 & 5.31 & 8.11 & 6.01 & 25 & 12.06 & 9.08 & 12.02 & 9.34 \\
\hline 26 & 8.42 & 5.33 & & & 26 & 11.58 & 9.19 & 11.59 & 9.31 \\
\hline 27 & 8.37 & 5.17 & & & 27 & 12.08 & 8.58 & & \\
\hline 28 & 8.49 & 5.27 & & & 28 & 12.07 & 9.05 & & \\
\hline 29 & 8.46 & 5.38 & & & 29 & 11.57 & 8.55 & & \\
\hline
\end{tabular}

After this, a statistical analysis on the Pearson chi-square test was carried out. The statistical value of the $\chi^{2}$ criterion for a group of students making preparation for the class 1 and working on the simulator is 31.173 , for the preparation of the class II it is 23.411 with a critical value of $\chi 2$ at a significance level $p<0.05$ equal to 17.708 . For a group working on acrylic teeth it is 15.380 , with a critical value of $\chi 2$ at the level of $p<0.05$. The relationship between the factor and the resulting indicators is statistically significant $[1,2]$.

After studying the questionnaires, it was revealed that out of 55 students, 13 people are sure that both methods of mastering the preparation of the teeth should be used. 42 students 
found the simulator more intuitive and understandable for mastering the principles of preparation (Figure 2).

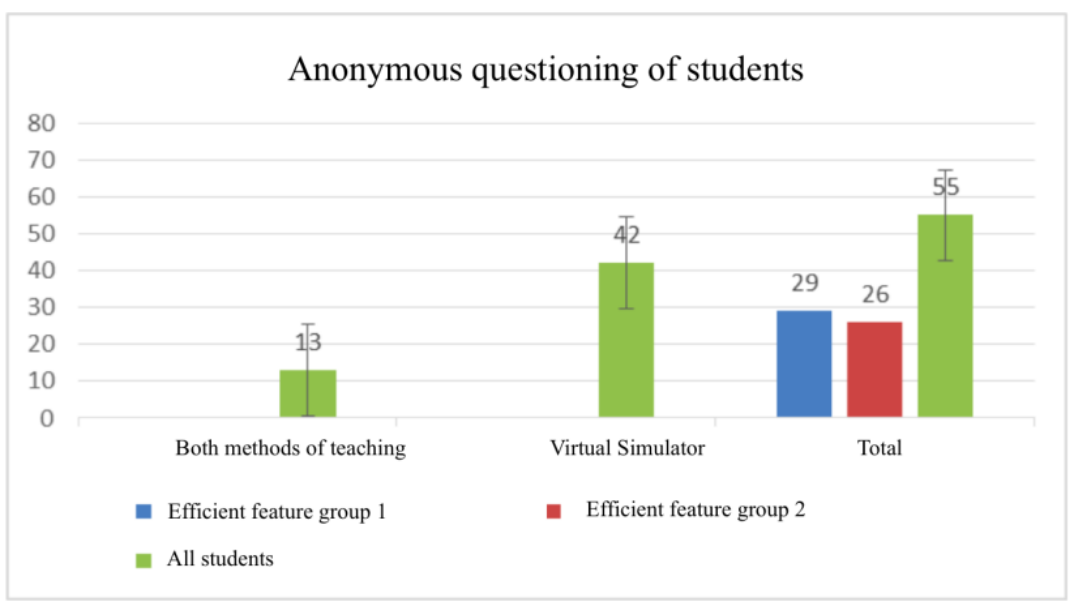

Fig. 2. The anonymous questioning of students on the assessment of the two teaching methods.

It should be noted that the assessment of the quality of preparation of acrylic teeth is subjective. Assessment of the quality of work on the virtual simulator is completely standardized and can be considered fully objective. Teachers and students who use this training system today confirm their greater effectiveness.

During the work, the trainees perform the task on the virtual jaw with a true sense of touch to the tooth, and the instructor can simply plan the course of work and assess the quality of the performed clinical task. In addition, different parts of the tooth have a certain color: enamel is gray, dentin is yellow, and the carious cavity is green. In this case, the physical presence of the teacher is not required, since the program itself evaluates and records everything the trainee makes.

The virtual simulator is characterized by a lack of repeatability, an unlimited range of clinical cases, training in real clinical situations from the most common to the rarest and complex ones, the possibility of mastering each specific case before obtaining the desired result, lack of need to purchase expensive supplies, and cleanliness in the room, because all clinical work takes place in a virtual environment.

\section{Conclusions}

Thus, the virtual simulator provides an innovative approach that allows creating with very high accuracy real tactile sensations and the sense of presence. When training on the simulator, there is no need to work with real patients that in turn allows getting rid of a number of shortcomings, namely, the human factor in evaluating the student's performance, as well as the issues related to the medical law. In addition, most students noted the positive effect of training on the virtual simulator that shows the need to introduce innovative technologies in the learning process.

The undoubted advantage of this technology is that there is no need to re-equip classrooms, and it can be easily built into the existing ones. Besides, it has an automated evaluation system, it is reliable and objective. All this can help the staff of dental departments standardize the decision-making. The absence of dust and water-dust aerosol should be considered the advantage of working with the virtual simulator. Despite its 
initially high cost, there is no need to buy new artificial teeth and burs. Also, this system can be used in the evaluation of final exams.

\section{References}

1. V. E. Gmurman, Guide to solving problems in the theory of probability and mathematical statistics (Higher Education, Moscow, 2006)

2. A. I. Prikhodko, Practice of Econometrics: regression analysis tools Excel (Phoenix, Rostov n /D, 2007)

3. C. Perrenot, M. Perez, N. Tran et al., Surgical Endoscopy, 26, 9 (2012)

4. S. Suebnukarn, P. Haddawy, P. Rhienmora, P. Jittimanee, and P. Viratket, Journal of Dental Education, 74, 12 (2010)

5. C. Luciano, P. Banerjee, and T. DeFenti, Virtual Reality, 13, 2 (2009) 